\title{
Subacute Inhalation Toxicity of 3-Methylpentane
}

\author{
Yong Hyun Chung, Seo-Ho Shin, Jeong Hee Han and Yong-Hoon Lee \\ Pathology Department, Chronic Inhalation Toxicity Research Center, Chemicals Toxicity Research Bureau, \\ Occupational Safety and Health Research Institute, Korea Occupational Safety and Health Agency, Daejeon, Korea
}

(Received April 7, 2016; Revised May 18, 2016; Accepted June 1, 2016)

\begin{abstract}
3-Methylpentane $\left(\mathrm{C}_{6} \mathrm{H}_{14}\right.$, CAS No. 96-14-0), isomer of hexane, is a colorless liquid originating naturally from petroleum or natural gas liquids. 3-Methylpentane has been used as a solvent in organic synthesis, as a lubricant, and as a raw material for producing carbon black. There is limited information available on the inhalation toxicity of 3-methylpentane, and the aim of this study was to determine its subacute inhalation toxicity. According to OECD Test Guideline 412 (subacute inhalation toxicity: 28-day study), Sprague Dawley rats were exposed to $0,284,1,135$, and $4,540 \mathrm{ppm}$ of 3-methylpentane for $6 \mathrm{hr} /$ day, 5 days/week for 4 weeks via whole-body inhalation. Mortality, clinical signs, body weights, food consumption, hematology, serum chemistry, organ weights, and gross and histopathological findings were compared between control and all exposure groups. No mortality or remarkable clinical signs were observed during the study. No gross or histopathological lesions, or adverse effects on body weight, food consumption, hematology, serum chemistry, and organ weights were observed in any male or female rats in all exposure groups, although some statistically significant changes were observed in food consumption, serum chemistry, and organ weights. In conclusion, the results of this study indicate that no observable adverse effect level (NOAEL) for 3-methylpentane above 4,540 ppm/6 hr/day, 5 days/week for rats.
\end{abstract}

Key words: 3-Methylpentane, NOAEL, Subacute inhalation toxicity

\section{INTRODUCTION}

3-Methylpentane $\left(\mathrm{C}_{6} \mathrm{H}_{14}\right.$, CAS No. 96-14-0), a volatile isomer of hexane (vapor pressure of $190 \mathrm{~mm} \mathrm{Hg}$ at $25^{\circ} \mathrm{C}$ ), is a colorless liquid originating naturally from petroleum or natural gas liquids (1). 3-Methylpentane is used as a solvent in organic synthesis, as a lubricant and as a raw material for producing carbon black (2,3). 3-Methylpentane released to the environment through various waste streams in the manufacture of polyolefins, synthetic rubbers, and some pharmaceuticals (4). The occupational exposure limit for mixtures containing nhexane and its isomers including 3-methylpentane is estimated to be $500 \mathrm{ppm}$ as time weighted average (TWA), and $1,000 \mathrm{ppm}$ as the short-term exposure limit (STEL) (3).

Correspondence to: Yong-Hoon Lee, Pathology Department, Chronic Inhalation Toxicity Research Center, Chemicals Toxicity Research Bureau, Occupational Safety and Health Research Institute, Korea Occupational Safety and Health Agency, 339-30 Exporo, Yuseong-gu, Daejeon 34122, Korea E-mail: dvmone@kosha.or.kr

This is an Open-Access article distributed under the terms of the Creative Commons Attribution Non-Commercial License (http:// creativecommons.org/licenses/by-nc/3.0) which permits unrestricted non-commercial use, distribution, and reproduction in any medium, provided the original work is properly cited.
The toxicity of 3-methylpentane has been rarely documented in humans and experimental animals. It can be estimated from hexane isomers including n-hexane, 2-methylpentane, and methylcyclopentane. Inhalation exposure of human to 3-methylpentane causes central nervous system symptoms including irritation, headache, drowsiness, dizziness, loss of coordination, convulsions, and coma. The liquid form of 3-methylpentane can cause eye, skin, respiratory and digestive irritation (2). Animals treated with n-hexane at $5,000 \mathrm{ppm}$ for 14 weeks or 2,500 ppm for 30 weeks developed typical giant axonal degeneration (5). Nephropathy related to alpha- $2 \mathrm{u}$ globulin was observed in male rats exposed to 2-methylpentane for 13 weeks via whole-body inhalation (6). Although hexane isomers have been reported to cause some adverse effects in laboratory animal, subacute inhalation toxicity information for 3-methylpentane is not available. Therefore, this study was conducted to characterize the potential subacute inhalation toxicity of 3-methylpentane by whole-body exposure in Sprague-Dawley (SD) rats in accordance with Good Laboratory Practice guideline.

\section{MATERIALS AND METHODS}

Animal husbandry and maintenance. Six-week-old specific-pathogen-free SD rats of both sexes were purchased 
from Japan SLC Inc. (Shizuoka, Japan) and acclimated for 1 week. The room was maintained at a temperature of $22 \pm$ $3^{\circ} \mathrm{C}$, relative humidity of $50 \pm 20 \%, 12: 12 \mathrm{hr}$ light : dark cycle, and fresh air ventilation (10 15 changes per hour). Rats were housed singly in stainless steel wire mesh cages (W $750 \mathrm{~mm} \times \mathrm{L} 220 \mathrm{~mm} \times \mathrm{H} 180 \mathrm{~mm}$ ) and had free access to a commercial rodent diet $\left(\right.$ LabDiet $^{\circledR}$, St. Louis, MO, USA) and filtered tap water. The study was conducted at Occupational Safety and Health Research Institute, and was approved by the Institutional Animal Care and Use Committee (IACUC-1504).

Test chemical and exposure system. 3-Methylpentane (lot no. MKBV3123V) was obtained from SigmaAldrich (St. Louis, MO, USA). A whole body stainless steel exposure chamber (SIS-20RG, Shibata, Niigata, Japan), including a gas generator (VG-4R, Shibata), was used to expose rats to 3-methylpentane at $0,284,1,135$, and 4,540 ppm for 6 hr/day, 5 days/week for 4 weeks. Exposures were done in accordance with test No. 412 (Subacute Inhalation Toxicity, 2009) by the Organization for Economic Co-operation and Development (OECD) (7). Inhalation exposures were conducted from 10:00 to 16:00. The experimental design was based on the routine working schedule of employees and the major exposure route for the test substance.

Conditions in the inhalation chambers. Temperature, relative humidity, pressure, and air ventilation in the chambers were recorded using an environmental controller (ICS20RG, Shibata). The concentrations of 3-methylpentane in the chambers were calibrated with a standard chemical (RIGAS, Daejeon, Korea). 3-Methylpentane was analyzed in a $1 \mathrm{~mL}$ gas sample by gas chromatography (GCS-14PFFS, Shimadzu Co., Kyoto, Japan) using a flame detector and a $0.5 \mathrm{~m}$ silicon DC-200 15\% Chromosorb (AW-DMCS) column with an 80/100 mesh. The detector, oven, and injector temperatures were 100,120 , and $120^{\circ} \mathrm{C}$, respectively. The vapor concentrations of 3-methylpentane in the chambers were measured every $15 \mathrm{~min}$ during the exposures, and were controlled to be within $\pm 5 \%$ of the target concentration using a computer. The mean concentration measured every $30 \mathrm{~min}$ for $6 \mathrm{hr}$ was taken as the value on a given day. This was then averaged over the 4 week exposure period to obtain the mean and standard deviation.

Experimental groups. A total of forty rats (20 males and 20 females) were assigned randomly to the following four groups (5 per sex per group): control $(0 \mathrm{ppm})$, low dose $(284 \mathrm{ppm})$, middle dose (1,135 ppm), and high dose $(4,540 \mathrm{ppm})$. All rats were euthanized after 4 weeks of treatment. The 3-methylpentane concentrations used were selected on the basis of an acute toxicity study performed previously (data not shown) using scaling factor $\times 4$ according to the Globally Harmonized System of Classification and Labeling of Chemicals.

Clinical signs, body weight, and food consumption. All animals were examined once daily for mortality and clinical signs, and weighed individually immediately before inhalation exposure on day 1 and once per week thereafter. Daily food consumption was evaluated before the initiation of inhalation and once per week thereafter. Food consumption was measured by subtracting remaining feed from the total feed supplied.

Hematology. All animals were fasted overnight before necropsy and blood collection. Blood samples were taken from the abdominal aorta using a syringe with a 24-gauge needle under Isoflurane anesthesia (Ilsung Pharm, Seoul, Korea) and were collected into vacutainers containing EDTA-3K (Becton Dickinson, Franklin Lakes, NJ, USA). Samples were analyzed within $20 \mathrm{~min}$ of collection using an automated hematology analyzer (Hemavet 950, Drew Scientific, Waterbury, CT, USA) and an automated coagulation analyzer (HumaClot Duo, Human, Wiesbaden, Germany) with plasma obtained after blood was mixed with $3.2 \%$ sodium citrate (9NC sodium citrate, Becton Dickinson). The following parameters were determined in this study: total erythrocyte counts (RBC), hemoglobin concentration (HGB), hematocrit (HCT), mean cell volume (MCV), mean cell hemoglobin $(\mathrm{MCH})$, mean cell hemoglobin concentration (MCHC), red cell distribution (RDW), platelet count (PLT), mean platelet volume (MPV), prothrombin time (PT) and activated partial thromboplastin time (APTT), whole leukocyte counts (WBC), neutrophils (NEU, \%), eosinophils (EOS, \%), basophils (BASO, \%), lymphocytes (LYM, $\%$ ) and monocytes (MONO, \%).

Serum biochemistry. Blood samples were centrifuged at 3,000 rpm for $10 \mathrm{~min}$ within $1 \mathrm{hr}$ after collection. Sera were stored at $-80^{\circ} \mathrm{C}$ before analysis. The following serum chemistry parameters were evaluated using an automated analyzer (TBA-20FR, Toshiba Medical Systems, Tochigi, Japan) and an electrolyte analyzer (DRI-CHEM 800, Fuji, Tokyo, Japan): total protein (TP), albumin (ALB), blood urea nitrogen (BUN), creatinine (CREA), total bilirubin (TBIL), alanine aminotransferase (ALT), aspartate aminotransferase (AST), lactate dehydrogenase (LDH), alkaline phosphatase (ALP), glucose (GLU), total cholesterol (TCHO), triglycerides (TG), CPK (Creatine Phosphokinase), calcium (Ca), inorganic phosphorus (IP), sodium $\left(\mathrm{Na}^{+}\right)$, and potassium $\left(\mathrm{K}^{+}\right)$, and chloride $\left(\mathrm{Cl}^{-}\right)$.

\section{Necropsy, organ weight, and histopathological evalua-}

tions. Gross examinations of organs in the cranial, thoracic, and abdominal cavities of the rats were conducted. The absolute and relative (organ to body weight) weights of the brain, thymus, lung, heart, liver, spleen, kidneys, adrenals, 
testes, and ovaries were measured. The following tissues were removed from each animal at necropsy: liver, kidney, adrenal gland, heart, lung, cerebrum, cerebellum, olfactory bulb, pituitary, spleen, seminal vesicle, prostate, testis, epididymis, ovary, uterus, vagina, tongue, trachea, esophagus, thymus, thyroid, stomach, duodenum, urinary bladder, small/ large intestine, eye/harderian gland, skeletal muscle, sciatic nerve, pancreas, aorta, mesenteric lymph node, femur, larynx, and nasal cavity. The nasal cavity was sectioned at three levels: 1 , posterior to the upper incisors; 2 , incisive papilla; 3, first molar teeth. The eyes were fixed in Davidson's solution and the testes in Bouin's solution. Other organs were preserved in $10 \%$ neutral buffered formalin. All organs were embedded in paraffin, sectioned at $3 \sim 4 \mu \mathrm{m}$, stained with hematoxylin and eosin, and examined microscopically with low and high power field.

Statistical analyses. Differences among groups in the various parameters were determined using SPSS (ver. 19.0, IBM, Chicago, IL, USA) or SigmaPlot (ver. 13.0, SYSTAT, San Jose, CA, USA) software. The homogeneity of variance was analyzed by Levene's test, followed by either oneway analysis of variance for samples with homogenous variance or the Kruskal-Wallis test for samples with heterogeneous variance. Duncan's or Dunnett's multiple range test was used to compare the result of each experimental group with that of the control group if the first statistical result was significant.

\section{RESULTS}

Chamber monitoring. The ranges of chamber conditions were $20.1 \sim 24.1^{\circ} \mathrm{C}, 51 \sim 63.3 \%$ relative humidity, $-9.4 \sim$ $-11 \mathrm{~mm} \mathrm{H}_{2} \mathrm{O}$ pressure, and $201.8 \sim 211.2 \mathrm{~L} / \mathrm{min}$ flow rate. The average concentrations of 3-methylpentane during the

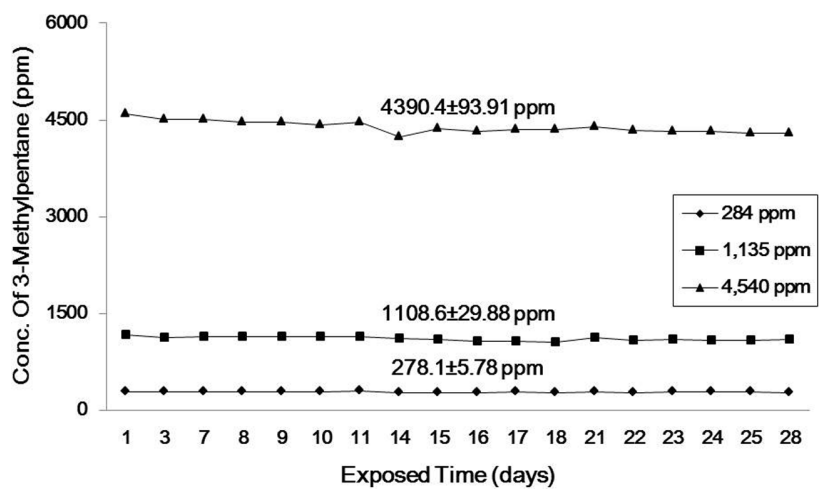

Fig. 1. 3-Methylpentane concentrations in the inhalation chamber during the study.

study were $278.1 \pm 5.78 \mathrm{ppm}, 1,108.6 \pm 29.88 \mathrm{ppm}$, and $4,390.4 \pm 93.91 \mathrm{ppm}$ for the low, medium, and high concentration groups, respectively. The daily mean chamber concentration was within $\pm 10 \%$ of the target concentration (Fig. 1).

Clinical signs. No deaths or adverse clinical signs were observed in any rats exposed to any concentration of 3methylpentane.

Body weight, and food consumption. Body weights did not changed significantly in any male or female rats exposed to any concentration of the 3-methylpentane (data not shown). Food consumption decreased significantly on day 10 in female rats exposed to 284 or $4,540 \mathrm{ppm}(p<$ 0.05) (Tables 1 and 2).

Hematology. No statistically significant hematological changes, in comparison with the control group, were observed

Table 1. Daily mean food consumption of male rats exposed to 3-methylpentane for 4 weeks

\begin{tabular}{ccccc}
\hline \hline Time (Day) & G1 (Control) & G2 $(284 \mathrm{ppm})$ & G3 (1,135 ppm) & G4 (4,540 ppm) \\
\hline 3 & $25.8 \pm 3.0$ & $27.2 \pm 2.9$ & $26.9 \pm 1.8$ & $26.2 \pm 1.4$ \\
10 & $25.2 \pm 2.1$ & $25.6 \pm 2.7$ & $25.1 \pm 2.8$ & $24.8 \pm 2.3$ \\
17 & $26.9 \pm 2.9$ & $27.7 \pm 2.8$ & $27.6 \pm 2.9$ & $25.8 \pm 1.2$ \\
24 & $25.8 \pm 2.7$ & $27.9 \pm 3.0$ & $26.4 \pm 1.2$ & $24.7 \pm 1.6$ \\
\hline
\end{tabular}

All values are expressed as mean \pm SD.

Table 2. Daily mean food consumption of female rats exposed to 3-methylpentane for 4 weeks

\begin{tabular}{ccccc}
\hline \hline Time (Day) & G1 (Control) & G2 $(284 \mathrm{ppm})$ & G3 $(1,135 \mathrm{ppm})$ & G4 $(4,540 \mathrm{ppm})$ \\
\hline 3 & $18.1 \pm 3.9$ & $17.6 \pm 3.8$ & $18.1 \pm 2.6$ & $19.6 \pm 1.9$ \\
10 & $20.0 \pm 4.5$ & $16.5^{*} \pm 2.8$ & $17.6 \pm 2.6$ & $16.4^{*} \pm 1.9$ \\
17 & $20.5 \pm 2.1$ & $20.5 \pm 2.9$ & $20.6 \pm 2.4$ & $19.3 \pm 2.0$ \\
24 & $21.6 \pm 4.1$ & $19.7 \pm 2.0$ & $19.3 \pm 1.4$ & $19.9 \pm 1.7$ \\
\hline
\end{tabular}

All values are expressed as mean \pm SD.

Significant differences as compared with the control group: ${ }^{*} p<0.05$. 
Table 3. Serum biochemical values of male rats exposed to 3-methylpentane for 4 weeks

\begin{tabular}{|c|c|c|c|c|c|}
\hline \multirow{2}{*}{ Tests } & \multirow{2}{*}{ Units } & \multicolumn{4}{|c|}{ Groups (ppm) } \\
\hline & & G1 (0) & G2 (284) & G3 $(1,135)$ & G4 $(4,540)$ \\
\hline $\mathrm{TP}$ & $\mathrm{g} / \mathrm{dL}$ & $6.0 \pm 0.1$ & $6.1 \pm 0.1$ & $6.1 \pm 0.2$ & $6.4^{*} \pm 0.3$ \\
\hline ALB & $\mathrm{g} / \mathrm{dL}$ & $3.86 \pm 0.11$ & $3.88 \pm 0.08$ & $3.86 \pm 0.09$ & $3.94 \pm 0.17$ \\
\hline BUN & $\mathrm{mg} / \mathrm{dL}$ & $16.5 \pm 2.2$ & $17.7 \pm 3.5$ & $15.7 \pm 1.7$ & $17.4 \pm 1.7$ \\
\hline CREA & $\mathrm{mg} / \mathrm{dL}$ & $0.50 \pm 0.07$ & $0.52 \pm 0.05$ & $0.52 \pm 0.05$ & $0.54 \pm 0.06$ \\
\hline TBIL & $\mathrm{mg} / \mathrm{dL}$ & $0.00 \pm 0.01$ & $0.00 \pm 0.01$ & $0.00 \pm 0.02$ & $0.00 \pm 0.03$ \\
\hline ALT & IU/L & $132.2 \pm 27.9$ & $125.63 \pm 17.1$ & $127.0 \pm 12.6$ & $130.80 \pm 25.2$ \\
\hline AST & $\mathrm{IU} / \mathrm{L}$ & $40.6 \pm 2.3$ & $47.0 \pm 5.8$ & $41.2 \pm 7.3$ & $40.6 \pm 4.0$ \\
\hline LDH & $\mathrm{IU} / \mathrm{L}$ & $2926.8 \pm 711.1$ & $2465.8 \pm 565.6$ & $2931.6 \pm 797.8$ & $3029.4 \pm 1075.2$ \\
\hline ALP & $\mathrm{IU} / \mathrm{L}$ & $611.2 \pm 70.7$ & $598.6 \pm 111.0$ & $542.4 \pm 83.2$ & $597.0 \pm 52.9$ \\
\hline GLU & $\mathrm{mg} / \mathrm{dL}$ & $141.0 \pm 8.3$ & $150.2 \pm 5.9$ & $149.8 \pm 7.4$ & $147.2 \pm 9.3$ \\
\hline TCHO & $\mathrm{mg} / \mathrm{dL}$ & $45.2 \pm 9.8$ & $47.4 \pm 14.1$ & $52.0 \pm 7.2$ & $60.2 \pm 9.7$ \\
\hline TG & $\mathrm{mg} / \mathrm{dL}$ & $29.2 \pm 14.9$ & $34.6 \pm 7.8$ & $33.0 \pm 9.3$ & $36.4 \pm 10.9$ \\
\hline CPK & IU/L & $994.4 \pm 326.6$ & $1039.4 \pm 517.9$ & $1128.8 \pm 328.0$ & $1125.6 \pm 532.6$ \\
\hline $\mathrm{Ca}^{2+}$ & $\mathrm{IU} / \mathrm{L}$ & $9.7 \pm 0.2$ & $9.8 \pm 0.2$ & $9.9 \pm 0.5$ & $10.1 \pm 0.2$ \\
\hline IP & $\mathrm{mg} / \mathrm{dL}$ & $7.8 \pm 1.0$ & $7.6 \pm 0.6$ & $7.8 \pm 0.8$ & $8.3 \pm 1.1$ \\
\hline $\mathrm{Na}^{+}$ & $\mathrm{mmol} / \mathrm{L}$ & $141.2 \pm 1.8$ & $141.2 \pm 0.8$ & $141.2 \pm 0.8$ & $141.2 \pm 0.8$ \\
\hline $\mathrm{K}^{+}$ & $\mathrm{mmol} / \mathrm{L}$ & $4.8 \pm 0.2$ & $4.9 \pm 0.3$ & $4.9 \pm 0.3$ & $4.9 \pm 0.4$ \\
\hline $\mathrm{Cl}^{-}$ & $\mathrm{mmol} / \mathrm{L}$ & $105.2 \pm 1.5$ & $103.6 \pm 0.9$ & $104.0 \pm 1.7$ & $104.2 \pm 1.3$ \\
\hline
\end{tabular}

All values are expressed as mean \pm SD.

Significant differences as compared with the control group: ${ }^{*} p<0.05$.

Table 4. Serum biochemical values of female rats exposed to 3-methylpentane for 4 weeks

\begin{tabular}{|c|c|c|c|c|c|}
\hline \multirow{2}{*}{ Tests } & \multirow{2}{*}{ Units } & \multicolumn{4}{|c|}{ Groups (ppm) } \\
\hline & & G1 (0) & G2 (284) & G3 $(1,135)$ & G4 $(4,540)$ \\
\hline $\mathrm{TP}$ & $\mathrm{g} / \mathrm{dL}$ & $6.7 \pm 0.5$ & $6.5 \pm 0.3$ & $6.7 \pm 0.1$ & $6.8 \pm 0.2$ \\
\hline ALB & $\mathrm{g} / \mathrm{dL}$ & $4.24 \pm 0.23$ & $4.08 \pm 0.11$ & $4.18 \pm 0.08$ & $4.30 \pm 0.10$ \\
\hline BUN & $\mathrm{mg} / \mathrm{dL}$ & $17.3 \pm 4.1$ & $17.7 \pm 3.4$ & $19.7 \pm 5.1$ & $15.6 \pm 1.6$ \\
\hline CREA & $\mathrm{mg} / \mathrm{dL}$ & $0.50 \pm 0.00$ & $0.48 \pm 0.05$ & $0.50 \pm 0.07$ & $0.50 \pm 0.00$ \\
\hline TBIL & $\mathrm{mg} / \mathrm{dL}$ & $0.10 \pm 0.01$ & $0.10 \pm 0.01$ & $0.10 \pm 0.00$ & $0.10 \pm 0.01$ \\
\hline ALT & IU/L & $130.0 \pm 29.2$ & $117.8 \pm 30.3$ & $132.8 \pm 9.3$ & $154.0 \pm 73.7$ \\
\hline AST & $\mathrm{IU} / \mathrm{L}$ & $43.8 \pm 11.5$ & $45.4 \pm 13.7$ & $40.4 \pm 4.0$ & $50.2 \pm 22.1$ \\
\hline $\mathrm{LDH}$ & $\mathrm{IU} / \mathrm{L}$ & $2402.2 \pm 767.4$ & $2212.2 \pm 927.1$ & $2107.4 \pm 689.9$ & $2004.8 \pm 985.5$ \\
\hline ALP & $\mathrm{IU} / \mathrm{L}$ & $336.2 \pm 62.5$ & $352.8 \pm 51.6$ & $318.2 \pm 104.9$ & $336.0 \pm 67.1$ \\
\hline GLU & $\mathrm{mg} / \mathrm{dL}$ & $146.0 \pm 25.2$ & $128.8 \pm 15.1$ & $124.4 \pm 20.6$ & $127.4 \pm 14.5$ \\
\hline TCHO & $\mathrm{mg} / \mathrm{dL}$ & $71.2 \pm 4.4$ & $79.0 \pm 12.8$ & $71.6 \pm 9.0$ & $82.4 \pm 13.0$ \\
\hline TG & $\mathrm{mg} / \mathrm{dL}$ & $18.2 \pm 5.1$ & $17.4 \pm 4.9$ & $14.0 \pm 4.2$ & $20.0 \pm 10.5$ \\
\hline $\mathrm{CPK}$ & $\mathrm{IU} / \mathrm{L}$ & $789.4 \pm 264.2$ & $685.2 \pm 318.7$ & $666.6 \pm 303.2$ & $536.4 \pm 208.8$ \\
\hline $\mathrm{Ca}^{2+}$ & $\mathrm{IU} / \mathrm{L}$ & $10.1 \pm 0.2$ & $10.1 \pm 0.2$ & $9.9 \pm 0.4$ & $10.3 \pm 0.2$ \\
\hline IP & $\mathrm{mg} / \mathrm{dL}$ & $7.2 \pm 0.6$ & $7.7 \pm 0.3$ & $7.8 \pm 0.3$ & $7.8 \pm 0.4$ \\
\hline $\mathrm{Na}^{+}$ & $\mathrm{mmol} / \mathrm{L}$ & $140.6 \pm 0.9$ & $141.4 \pm 0.6$ & $141.2 \pm 0.8$ & $141.4 \pm 0.6$ \\
\hline $\mathrm{K}^{+}$ & $\mathrm{mmol} / \mathrm{L}$ & $4.8 \pm 0.3$ & $4.6 \pm 0.7$ & $4.7 \pm 0.5$ & $4.9 \pm 0.2$ \\
\hline $\mathrm{Cl}^{-}$ & $\mathrm{mmol} / \mathrm{L}$ & $104.4 \pm 2.0$ & $103.0 \pm 1.9$ & $103.8 \pm 1.9$ & $102.8 \pm 3.2$ \\
\hline
\end{tabular}

All values are expressed as mean \pm SD.

in any of all the groups exposed to 3-methylpentane (data not shown).

Serum biochemistry. Total protein was increased significantly in male rats exposed to 4,540 ppm 3-methylpentane, compared to the control group $(p<0.05)$ (Tables 3 and $4)$. There were no changes in other parameters.
Organ weight. No statistically significant changes in absolute organ weight were observed in any of the 3-methylpentane groups in comparison with the control group (data not shown). However, the relative liver weights was increased significantly in male rat exposed to 4,540 ppm 3methylpentane group compared to that in the control group $(p<0.01)$ (Tables 5 and 6). 
Table 5. Relative organ weights of male rats exposed to 3-methylpentane for 4 weeks

\begin{tabular}{|c|c|c|c|c|}
\hline \multirow{2}{*}{ Organ weights (\%) } & \multicolumn{4}{|c|}{ Groups (ppm) } \\
\hline & G1 (0) & G2 (284) & G3 $(1,135)$ & G4 $(4,540)$ \\
\hline Body weight (g) & $318.52 \pm 18.99$ & $316.72 \pm 11.10$ & $326.14 \pm 12.37$ & $316.18 \pm 10.04$ \\
\hline Adrenal glands & $0.020 \pm 0.003$ & $0.021 \pm 0.006$ & $0.022 \pm 0.001$ & $0.020 \pm 0.002$ \\
\hline Brain & $0.630 \pm 0.036$ & $0.621 \pm 0.027$ & $0.617 \pm 0.020$ & $0.623 \pm 0.023$ \\
\hline Heart & $0.314 \pm 0.019$ & $0.305 \pm 0.010$ & $0.313 \pm 0.009$ & $0.305 \pm 0.010$ \\
\hline Kidneys & $0.684 \pm 0.047$ & $0.661 \pm 0.026$ & $0.684 \pm 0.017$ & $0.668 \pm 0.022$ \\
\hline Liver & $2.544 \pm 0.091$ & $2.632 \pm 0.095$ & $2.719 \pm 0.097$ & $2.848 \pm 0.144^{* *}$ \\
\hline Spleen & $0.178 \pm 0.022$ & $0.188 \pm 0.022$ & $0.189 \pm 0.015$ & $0.195 \pm 0.007$ \\
\hline Lung & $0.377 \pm 0.011$ & $0.370 \pm 0.019$ & $0.377 \pm 0.020$ & $0.374 \pm 0.026$ \\
\hline Testes & $1.050 \pm 0.113$ & $1.002 \pm 0.055$ & $1.008 \pm 0.067$ & $1.009 \pm 0.038$ \\
\hline Thymus & $0.120 \pm 0.022$ & $0.123 \pm 0.020$ & $0.134 \pm 0.021$ & $0.131 \pm 0.016$ \\
\hline
\end{tabular}

All values are expressed as mean \pm SD.

Significant differences as compared with the control group: ${ }^{* *} p<0.01$.

Table 6. Relative organ weights of female rats exposed to 3-methylpentane for 4 weeks

\begin{tabular}{|c|c|c|c|c|}
\hline \multirow{2}{*}{ Organ weights (\%) } & \multicolumn{4}{|c|}{ Groups (ppm) } \\
\hline & G1 (0) & G2 (284) & G3 $(1,135)$ & G4 $(4,540)$ \\
\hline Body weight (g) & $207.68 \pm 12.20$ & $208.66 \pm 13.64$ & $199.92 \pm 4.82$ & $201.92 \pm 9.93$ \\
\hline Adrenal glands & $0.034 \pm 0.004$ & $0.034 \pm 0.003$ & $0.037 \pm 0.005$ & $0.035 \pm 0.003$ \\
\hline Brain & $0.898 \pm 0.069$ & $0.913 \pm 0.068$ & $0.934 \pm 0.029$ & $0.928 \pm 0.053$ \\
\hline Heart & $0.371 \pm 0.019$ & $0.358 \pm 0.022$ & $0.357 \pm 0.031$ & $0.363 \pm 0.018$ \\
\hline Kidneys & $0.744 \pm 0.036$ & $0.765 \pm 0.069$ & $0.766 \pm 0.043$ & $0.760 \pm 0.043$ \\
\hline Liver & $2.669 \pm 0.170$ & $2.658 \pm 0.136$ & $2.649 \pm 0.095$ & $2.713 \pm 0.114$ \\
\hline Ovaries & $0.053 \pm 0.009$ & $0.055 \pm 0.007$ & $0.053 \pm 0.007$ & $0.046 \pm 0.005$ \\
\hline Spleen & $0.205 \pm 0.011$ & $0.212 \pm 0.022$ & $0.210 \pm 0.008$ & $0.195 \pm 0.017$ \\
\hline Lung & $0.447 \pm 0.032$ & $0.478 \pm 0.052$ & $0.483 \pm 0.017$ & $0.484 \pm 0.025$ \\
\hline Thymus & $0.172 \pm 0.023$ & $0.182 \pm 0.023$ & $0.191 \pm 0.013$ & $0.163 \pm 0.015$ \\
\hline
\end{tabular}

All values are expressed as mean \pm SD.

Gross and histopathological evaluations. No gross lesions were observed in any 3-methylpentane group except for nodules of the cauda of the left epididymis in a male rat exposed to 1,135 ppm 3-methylpentane group. No histopathological finding were observed in any organ of the control group or any of the 3-methylpentane exposed group other than the nodules of the cauda of the left epididymis.

\section{DISCUSSION}

This study was performed to evaluate the potential subacute toxicity of 3-methylpentane by a 4 week repeated inhalation exposure to SD rats at concentrations of to 0 , $284,1,135$, and $4,540 \mathrm{ppm}$. Although we found some statistically significant differences in food consumption, serum chemistry, and organ weights in 3-methylpentane exposed animals in comparison with the control group, no physiological or pathological adverse effects were observed.

Any clinical signs were not observed in any rats exposed to any concentration of 3-methylpentane. Previous report indicated that 3-methylpentane caused central nervous system, eye, skin, respiratory and digestive clinical signs in human (2). Species differences and exposure route may contribute to the differences between the previous study and our study.

Statistically significant changes in food intake were observed on day 10 in female rats exposed to 284 and 4,540 ppm 3-methylpentane group. However, these changes were not considered to be an adverse effect because the changes were not dose-dependent and the animals recovered indicating these changes were transient (8).

A decrease of total serum protein was observed in male rats exposed to 4,540 ppm 3-methylpentane compared to the control groups. This change was also not considered to be an adverse effect because it was not observed in females and did not correlate with other serum biochemistry parameter such as ALB, or with morphological alterations in liver or kidney (8). A previous study reported an increase of TP was observed in male rats exposed to 4,640 ppm of 2-methylpentane for 13 weeks via whole-body inhalation (6). However, this change could be attributed to alpha- $2 \mathrm{u}$ globulin nephropathy, a sex - and species-specific lesion of male rats $(6,9)$.

There were statistically significant increases in the rela- 
tive organ weight of livers in males of the 4,540 ppm group. However, these changes were not regarded to be adverse effects because they were not dose-dependent nor accompanied by an increase in the absolute organ weight of livers, or alterations of serum chemical markers of liver injury, and not associated with histopathological alterations in the liver (8). Furthermore, if liver weight caused by hypertrophy and hyperplasia does not involve an increase up to $20 \%$, and is not accompanied by histopathological changes, it is not considered as an adverse effect in rodents (10). Finally, the increase of liver organ weight can be regarded as an adverse effect only if accompanied by alterations in parameter of hepatobiliary damage or dysfunction $(11,12)$.

Histopathological examination revealed a nodule of the cauda of the left epididymis that correlated with a moderately severe granuloma. This is a known spontaneous lesion of rodents (13).

In conclusion, a 4-week repeated whole-body inhalation exposure of rats to three concentrations of 3-methylpentane didn't result in any toxic effects. Thus, the no observable adverse effect level (NOAEL) was considered to be above $4,540 \mathrm{ppm} 6 \mathrm{hr} /$ day, 5 days/week for rats. The present study provides useful information regarding the lack of toxicity of inhaled 3-methylpentane.

\section{ACKNOWLEDGMENTS}

This work was supported by the Korea Occupational Safety and Health Agency, Ministry of Labor, Republic of Korea, and a Grant-in-Aid for chemical hazard assessment, 2015.

\section{REFERENCES}

1. Bingham, E., Cohrssen, B. and Powell, C.H. (2001) Patty's Toxicology Volumes 1-9 (5th edition), John Wiley \& Sons, New York, pp. 4-43.

2. MATHESON. Material Safety Data Sheet. Available from: https:/www.mathesongas.com/pdfs/msds/MAT29460.pdf.
3. U.S. National Library of Medicine. Hazardous Substances Data bank. (Substance name: 3-methylpentane) Available from: http://toxnet.nlm.nih.gov/cgi-bin/sis/search2/f?./temp/ rVVliU:1.

4. Lewis, R.J., Sr. (2001) Hawley's Condensed Chemical Dictionary (14th edition), John Wiley \& Sons, New York, p. 743.

5. Frontali, N., Amantini, M.C., Spagnolo, A., Guarcini, A.M., Saltari, M.C., Brugnone, F. and Perbellini, L. (1981) Experimental neurotoxicity and urinary metabolites of the C5-C7 aliphatic hydrocarbons used as glue solvents in shoe manufacture. Clin. Toxicol., 18, 1357-1367.

6. Chung, Y.H., Lim, C.H. and Han, J.H. (2014) A study on subchronic inhalation toxicity of 2-methylpentane. J. Korean Soc. Occup. Environ. Hyg., 24, 169-181.

7. OECD (2009) Test No. 412: Subacute Inhalation Toxicity: 28Day Study in OECD guideline for the testing of chemicals, Section 4. Available from: http://www.oecd-ilibrary.org/environment/test-no-412-subacute-inhalation-toxicity-28-day-study_ 9789264070783-en.

8. Lewis, R.W., Billington, R., Debryune, E., Gamer, A., Lang, B. and Carpanini, F. (2002) Recognition of adverse and nonadverse effects in toxicity studies. Toxicol. Pathol., 30, 66-74.

9. Frazier, K.S., Seely, J.C., Hard, G.C., Betton, G., Burnett, R., Nakatsuji, S., Nishikawa, A., Durchfeld-Meyer, B. and Bube, A. (2012) Proliferative and nonproliferative lesions of the rat and mouse urinary system. Toxicol. Pathol., 40, 14S-86S.

10. Karbe, E., Williams, G.M., Lewis, R.W., Kimber, I. and Foster, P.M. (2002) Distinguishing between adverse and nonadverse effects. Session summary. Exp. Toxicol. Pathol., 54, 51-55.

11. Amacher, D.E., Schomaker, S.J. and Burkhardt, J.E. (1998) The relationship among microsomal enzyme induction, liver weight and histological change in rat toxicology studies. Food Chem. Toxicol., 36, 831-839.

12. Hall, A.P., Elcombe, C.R., Foster, J.R., Harada, T., Kaufmann, W., Knippel, A., Kuttler, K., Malarkey, D.E., Maronpot, R.R., Nishikawa, A., Nolte, T., Schulte, A., Strauss, V. and York, M.J. (2012) Liver hypertrophy: a review of adaptive (adverse and non-adverse) changes-conclusions from the 3rd International ESTP Expert Workshop. Toxicol. Pathol., 40, 971-994.

13. Boorman, G.A., Eustis, S.L., Elwell, M.R., Montgomery, C.A., Jr. and Mackenzie, W.F. (1990) Pathology of the Fischer rat, Academic Press, San Diego, pp. 99-100. 